\title{
Algumas Implicações Políticas, (Po)éticas e Práticas no Projeto “Diferenças e Alteridade na Educação: saberes, práticas e experiências (inclusivas) na rede pública de ensino em São Gonçalo"1
}

Anelice Ribetto ${ }^{2}$

\section{RESUMO}

Algumas implicações políticas, (po)éticas e práticas no projeto "Diferenças e Alteridade na Educação: saberes, práticas e experiências (inclusivas) na rede pública de ensino em São Gonçalo”. Esse trabalho traz algumas questões conceituais para nos ajudar a produzir um primeiro exercício de pensamento sobre as implicâncias políticas, práticas e poéticas no projeto de pesquisa "Diferenças e alteridade na educação: saberes, práticas e experiências (inclusivas) na rede pública de ensino em São Gonçalo” iniciado em março de 2011 na UERJ/Faculdade de Formação de Professores. A tentativa do projeto é compreender de que forma se vem materializando a educação inclusiva nas escolas da rede e as repercussões nas práticas, saberes e experiências dos seus professores. Assim, a pesquisa pretende recolher nas narrativas, as formas com que as professoras negociam -ao conviverem- com diferentes lógicas, línguas e sentidos do mundo nos encontros cotidianos escolares, na diferença.

Palavras-chave: diferenças; alteridade; políticas de educação inclusiva.

\section{ABSTRACT}

Political,Practicaland(Po)ethicalImplicationsintheResearchProject “Differencesandalterity ineducation:knowledge, practicesand(inclusive)experiencesatpublicschoolsinSãoGonçalo”. This work brings some conceptual issues to help us to think about the political, practical and (po) ethical implications in the research project "Differences and alterity in education: knowledge, practices and (inclusive) experiences at public schools in São Gonçalo. The project started in March 2011 at UERJ/Faculdade de Formação de Professores and it tries to improve the understanding about how inclusive education is taking place at schools and how is it impact on teachers' practices, knowledge and experiences. Through narratives, the research aims to present in which way teachers negotiate and deal with the difference using diverselogic, languages and sense in daily life at schools.. Key words: difference; alterity; inclusive education policies.

\footnotetext{
1Esse artigo é um desdobramento e um aprofundamento das questões trabalhadas na comunicação Saberes, Práticas e Experiências (inclusivas) na Rede Pública de Ensino de São Gonçalo da minha autoria, com co-autorias de Gilcelia Coelho da Silva Baptista e Leidiane dos Santos Aguiar Macambira, apresentado no I Seminário Currículos, cotidianos, culturas e formação de educadores, 2011, Vitória. Publicado nos Anais do I Seminário Textos Completos. Vitória : NUPEC, 2011. p. 1464-1476;

2 Professora Adjunta do Departamento de Educação e do Mestrado em Educação: Processos Formativos e Desigualdades Sociais da Faculdade de Formação de Professores da Universidade do Estado do Rio de Janeiro. Contato: $\underline{\text { anelatina@gmail.com }}$
} 
Algumas Implicações Políticas, (Po)éticas e Práticas no Projeto “Diferenças e Alteridade na Educação:...

¿qué otra cosa podriamos hacer sino poner en cuestión los modos de relación que habitamos y que nos habitan? (Carlos Skliar)

Este ensaio tem como desejo compartilhar algumas questões para produzir um exercício de pensamento sobre as implicações políticas, práticas e (pó)éticas levantadas através de um projeto de pesquisa desenvolvido em uma universidade pública brasileira, entendendo essas questôes como atravessamentos entre a Educação Especial e a Educação Fundamental a partir das políticas contemporâneas de educação inclusiva que garantem a escolaridade dos alunos com necessidades educacionais especiais na rede regular de ensino. A tentativa do referido projeto é compreender de que forma se vem materializando a educação inclusiva nas escolas públicas de ensino da rede e as repercussões nas práticas, saberes e experiências dos seus professores. Assim, a pesquisa pretende recolher nas narrativas, as formas com que as professoras negociam -ao conviveremcom diferentes lógicas, línguas e sentidos do mundo nos encontros cotidianos escolares, na diferença.

A Política Nacional de Educação Inclusiva (BRASIL, 2008) define como objetivo assegurar a participação e a aprendizagem aos estudantes com deficiências, transtornos globais do desenvolvimento e altas habilidades/superdotação nas escolares ditas comuns do ensino regular. De acordo com este objetivo, a educação especial é considerada como uma modalidade transversal a todos os níveis, etapas e modalidades do ensino, que se desenvolve de forma complementar ou suplementar, disponibilizando serviços e recursos para as atividades de atendimento educacional especializado.

Considerando, então, a educação especial como modalidade transversal, entendemos que este trabalho pode colaborar em pensar a mesma já não como área ou campo especifico, mas como um atravessamento político, poético e prático na educação básica como um todo, especialmente porque o encontro pedagógico, aquele que acontece no cotidiano das escolas, se produz entre professores, pais e alunos da rede regular do ensino e não mais em escolas especiais segregadas. Entendemos que propor esse trabalho ao campo da Educação Fundamental coloca relevo numa necessidade política contemporânea: incluir a consideração e a análise dos acontecimentos que se produzem na educação dos alunos com deficiências dentro dos problemas educacionais gerais e não, como tem feito histórica e hegemonicamente, fora deles e quanto mais longe, melhor, por o fato de que a educação especial esteja virtualmente excluída do debate educacional é a primeira e mais importante discriminação sobre a qual, depois, se projetam sutilmente todas as demais discriminações 


\title{
Implicações políticas...
}

A chamada Educação Inclusiva é, contemporaneamente, política educacional oficializada do Brasil, inspirada e amparada pela legislação internacional e transformada em diretrizes para a Educação Básica dos sistemas federal, estaduais e municipais. Ainda que a legislação brasileira, no referente a Educação Inclusiva, possa ser considerada bastante avançada tendo em vistas os padrões internacionais, a promulgação de leis e diretrizes políticas e pedagógicas não garante, necessariamente, que os desdobramentos se concretizem efetivamente no cotidiano tal qual os discursos jurídicos prevêem. Concebemos as chamadas políticas da inclusão como um processo que busca responder aos anseios e lutas dos movimentos sociais contemporâneos por direitos de igualdade e de diferença. Essa concepção tem também uma marca inspirada nas perspectivas interculturais. Tais perspectivas que,"tentam ser menos vigilantes e menos pretensiosas que as perspectivas tradicionais da educação especial- tratam de inverter a lógica e o poder da normalidade" (SKLIAR,2005) fazendo dela o problema em questão: desmitificar o normal, perdem cada um e todos os parâmetros instalados na pedagogia sobre o que é "correto", pensar mais cuidadosamente sobre essa invenção maléfica do outro "anormal", etc. Neste sentido, no que nosso trabalho se enquadra, pensa a educação especial (suas políticas, praticas, experiências, saberes) como um dispositivo que torna problemática e insustentável a ideia do "normal" do comportamento, do corpo, da sexualidade, da aprendizagem, etc. Sabemos que

\begin{abstract}
Educação para Todos, Cidadania, Inclusão, Direito à Diversidade, Pluralidade Cultural, Educação nas Diferenças, [Diferenças e alteridade na Educação]são expressões muito utilizadas nos dias de hoje, mas que, apropriadas por diferentes discursos e interesses político-ideológicos, soam, muitas vezes, como meros clichês, num mundo que produz cada vez mais excluídos. Palavrasconceitos muitas vezes esvaziadas de sentidos, ou produzindo sentidos outros para nomear os sujeitos considerados como material de descarte na economia globalizada. Portanto, para tentar entender os múltiplos sem-sentidos, sentidos e significados implícitos nesses conceitos, é fundamental situá-los no contexto das tensões e das mudanças provocadas pela globalização neoliberal e pela crise de paradigmas da modernidade nas nossas sociedades contemporâneas (PEDREIRA, S., 2007, p.1).
\end{abstract}

Mas, Como essas lutas foram se traduzindo em marcos jurídicos para pensar a Educação Inclusiva? Sinteticamente, e inspirados em análise $e^{3}$ realizada em 2010 por Márcia Pletsch, podemos dizer que a partir do ano 1993, uma série de movimentos políticos vem sendo produzidos no sentido de provocar algumas mudanças que assegurem o ingresso e a permanência de todos os alunos na escola. Como por exemplo, quando o Brasil é convidado para participar da conferência de Nova Delhi, na qual se reiteraram os compromissos assumidos em Joentiem, em relação à Declaração de Educação Para Todos.

3 Essa análise é um recorte que pode ser ampliado em PLETSCH, Márcia Denise. Repensando a inclusão escolar: diretrizes políticas, práticas curriculares e deficiência intelectual. Rio de Janeiro: NAU; EDUR, 2010; 
Em 1994, foi realizada a Conferência Mundial sobre Necessidades Educacionais Especiais: acesso e qualidade, promovida pelo governo espanhol e a UNESCO, que resultou na Declaração de Salamanca (1994). Este documento é tomado como referência no campo da Educação Especial para a instituição do termo "inclusão escolar" (BUENO, 2008). Assim, difundida rapidamente, a declaração passou a influenciar a elaboração de políticas públicas e práticas educacionais em inúmeros países. Segundo Plestch

Desde então, a política de inclusão de alunos com deficiências no ensino regular vem sendo fortalecida e nos últimos anos mediante a promulgação de diversas diretrizes governamentais. O Plano Nacional de Educação (BRASIL, 2000), por exemplo, fixou objetivos e metas a serem cumpridos a curto e médio prazos, visando o aprimoramento da educação e do atendimento das chamadas pessoas com necessidades educacionais especiais. No mesmo ano, as Diretrizes Nacionais para Educação Especial na Educação Básica (BRASIL, 2001) oficializaram em nosso país os termos "educação inclusiva" e "necessidades educacionais especiais", regulamentaram a organização e a função da Educação Especial nos sistemas de ensino, bem como as modalidades de atendimento (p.6)[...] A um diverso grupo de dispositivos jurídico-institucionais foi agregado, em 2007, oPlano de Desenvolvimento da Educação (PDE). Entre outras medidas, este plano estabelece metas para o acesso e a permanência no ensino regular e o atendimento às necessidades educacionais especiais dos alunos, fortalecendo a inclusão educacional nas escolas públicas (BRASIL, 2007). Em janeiro de 2008, a SEESP apresentou uma nova versão da Política Nacional de Educação Especial na Perspectiva da Educação Inclusiva, prevendo o atendimento especializado em salas de recursos e centros especializados de referência (BRASIL, 2008). A referida política, regulamentada em outubro de 2009, vem sendo amplamente difundida pela Secretaria de Educação Especial e orienta as redes de ensino a se transformarem em "sistemas educacionais inclusivos", já em sintonia com os princípios da Convenção Internacional sobre os Direitos das Pessoas com Deficiência, conhecida como Declaração da Organização das Nações Unidas (ONU), aprovada pela Câmara dos Deputados em 13 de maio de 2008. Ainda em 2008, o Decreto $n^{\circ}$. 6.571, promulgado em setembro, dispõe sobre o apoio técnico e financeiro aos sistemas públicos de ensino dos estados, do Distrito Federal e dos municípios que prestarem atendimento educacional especializado aos alunos com deficiência, transtornos globais do desenvolvimento e altas habilidades, matriculados na rede pública de ensino (BRASIL, 2008a). Por meio desse decreto é considerado atendimento educacional especializado "o conjunto de atividades, recursos de acessibilidade e pedagógicos organizados institucionalmente, prestado de forma complementar ou suplementar à formação dos alunos no ensino regular" (Art. $1^{\circ}$, $\left.\S 1^{\circ}\right)$, conforme previsto na já citada Política Nacional de Educação Especial na Perspectiva da Educação Inclusiva (BRASIL, 2008). A partir de $1^{\circ}$ de janeiro de 2010, o referido decreto passará a regulamentar a distribuição dos recursos do FUNDEB para "o cômputo das matrículas dos alunos da educação regular da rede pública que recebem atendimento educacional especializado, sem prejuízo do cômputo dessas matrículas na Educação Básica regular (Art. 9)”. (PLESCH, 2010, p.5).

A legislação aqui citada é um dos marcos que permite pensar alguns aspectos da educação especial na perspectiva da educação inclusiva nas escolas regulares, fundamentalmente tendo em conta a tensão entre a linguagem, jurídica expressada nos documentos, e a linguagem ética que atravessa as micropolíticas, experiências, saberes e práticas no cotidiano escolar. Essa questão é fundamental para continuar a pensar nas formas que podemos reler esse marco jurídico da educação inclusiva, reflexão que enunciamos no começo desse texto. Talvez, trate-se de uma relação de ambiguidade entre a razão jurídica -expressada no corpo da lei- e a razão ética -encarnada na intimidade das políticas (SKLIAR, 2010). A inclusão é assumida, muitas vezes, somente o ponto de vista de um 
conjunto de direitos inquestionáveis: o direito a uma educação igualitária, o direito a uma escola para todos, o direito de educar para a diversidades, etc. Mas, “ o que acontece quando a razão jurídica se apresenta em excesso, ou seja, quando se apresenta como a única razão ou, inclusive, quando se apresenta como condição anterior, como precedência, ao que poderíamos chamar como a razão ética?”‘(SKLIAR, 2010, p.161)

É essa relação de tensão entre as questões jurídicas e as questões éticas o que nos fez pensar em focar nosso olhar nas micropolíticas, experiências, saberes e práticas no cotidiano escolar como território privilegiado para experimentar essas tensões.

\section{Implicações práticas...}

Uma primeira implicação na prática que essa experiência de pesquisa vem possibilitando: repensarmos essa tensão significativa que traz a necessidade de "estarmos juntos" na educação. Neste caso especifico, esse estar juntos na escola viu-se expandido no Brasil, fundamentalmente, através das políticas públicas posteriores a 2008 que não mais legitimam um espaço material e simbólico paralelo à escola regular para os alunos da educação especial. Carlos Skliar discute a existência de um equívoco, ou de uma apropriação dos sentidos do que significaria estar juntos como se esse acontecimento fosse alguma coisa sempre ligada a uma suposta harmonia, uma ausência de conflito, uma tranquilidade relacional prévia e, muitas vezes, prescrita e antecipada antes mesmo do encontro pedagógico.

Há um equívoco desde o início da discussão sobre a convivência e o estar juntos na educação: nem uma nem o outro podem ser pensadas como flechas, signos, símbolos ou indicações direcionadas necessariamente para a harmonia, a não conflictividade, o acordo instantâneo, a empatia imediata, a plena satisfação educativa. Talvez nessa crença esteja o erro primordial e a maior desvirtuação do problema: se, talvez, partíssemos da ideia que a convivência é pura ambiguidade, afeição, contradição, fricção, não procuraríamos resolver a vida em comum a partir de fórmulas fantasiadas de bons hábitos e costumes, morais industrializadas, didáticas do bemestar e do bem-dizer, valores absolutos, ou laboratórios de diálogos já pré-construídos ${ }^{5}$ (SKLIAR, C., 2009, p.2).

4 Tradução da autora: qué ocurre cuando la razón jurídica se presenta en exceso, esto es, cuando se presenta como la única razon o, inclusive, cuando se presenta como condición anterior, como precedencia, a lo que podríamos llamar como la razón ética.

5 Tradução da autora: "Hay un equívoco desde el inicio de la discusión sobre la convivencia y el estar-juntos en educación: ni la una ni la otra pueden ser pensadas como flechas, signos, símbolos o indicaciones que apuntan necesariamente hacia la armonía, la no conflictividad, el acuerdo instantáneo, la empatía inmediata, la plena satisfacción educativa. Tal vez en ello radique el primordial error y la mayor desvirtuación del problema: si acaso partiéramos de la idea que la convivencia es pura ambigüedad, afección, contradicción, fricción, no buscaríamos resolver la vida en común a partir de fórmulas solapadas de buenos hábitos y costumbres, morales industrializadas, didácticas del bienestar y del bien-decir, valores insospechables, o necios laboratorios de diálogos ya preconstruidos". 
Nessa falsa expectativa radica, talvez, a máxima armadilha que nos fez, e ainda faz, pensar nos encontros pedagógicos como alguma coisa ausente da complexidade e da possibilidade de conflito. Esperando esse céu na terra, qualquer cotidiano terreno é significado como falta dessa harmonia e é exigido um ato heróico para possibilitar esse estar juntos. Skliar (2009) convida a nos perguntar com ele "o que está em evidência ao pensar no destino educativo da convivência, se quase tudo o que se faz é andar pelas bordas de uma certa aceitação empurrada do outro?”, e continua, "não seria possível assumir de uma vez que a crise educativa é clara e contundentemente uma crise da convivência?" $(p .7)^{6}$

A partir desta discussão proposta por Skliar, a pesquisa movimenta-se e tensiona a produção de políticas e práticas. Com isto, há a emergência de outros problemas que se desdobram e redimensionam os enfrentamentos com o cotidiano/ou com as experiências/ ou com as micropolíticas...

Quem é a criança, jovem, adolescente ou adulto com deficiência que tem acesso à escola pública? O direito de matrícula garante a mesma qualidade de permanência na educação infantil, no ensino fundamental regular ou na modalidade de educação de jovens e adultos? Matriculamse na escola regular por opção pedagógica? As famílias têm a acesso às possibilidades que esta escola irá fornecer ao seu filho? Quem é o "todos"? [...] Quais adequaçôes realizam para cumprir as determinações legais? Como adequar o que é plural às particularidades daquela comunidade? Qual a compreensão teórica do processo de construção/produção do conhecimento? Quais ofertas de serviços de apoio pedagógico? Como os profissionais de uma determinada unidade educacional analisam e dimensionam a prática educativa permitindo o sucesso ou o fracasso escolar dos alunos? A discussão não se limita ao aceite às diferenças, mas como se compreende e consequentemente lida com as relações de poder inerentes nas relações das diferenças? Qual a estruturação material e a disponibilidade de meios simbólicos que permitam a organização de práticas culturais em diferentes domínios - espaços e tempos escolares? (SILVA, S., 2007, p.3-4).

\section{Implicações (po)éticas...}

Talvez, experimentando a aridez dessas perguntas, possamos pensar nas implicações que esse projeto de pesquisa traz: repensar o campo de pesquisa, o campo da Educação Especial. Pensálo como um plano de tensões, intenções e desdobramentos no qual as chamadas políticas da educação inclusiva e os seus efeitos nas práticas escolares necessitam ser, pelo menos, relidas... Talvez, menos literalmente e mais poeticamente, quer dizer, lidas de uma forma que nos afaste ainda mais da materialidade das leis, mas que nos permita entender algumas questões que estão

6 Tradução da autora: “¿qué se pone en evidencia al pensar en el destino educativo de la convivencia, si casi todo lo que se hace es merodear por los bordes de una cierta aceptación a regañadientes del otro?, ¿no sería posible asumir de una vez que la crisis educativa es clara y contundentemente una crisis de la convivencia (y, por lo tanto, de la transmisión, y de la experiencia, y de la herencia, y de la conversación)?” 
na intimidade dessas políticas, como questão ética e estética. Trata-se de tentar compreender como se relacionam a linguagem jurídica com a paixão ética e os seus possíveis desdobramentos no campo das práticas escolares cotidianas.

É essa relação de tensão entre as questões jurídicas e as questões éticas o que nos fez pensar em focar nosso olhar nas micropolíticas, experiências, saberes e práticas no cotidiano escolar como território privilegiado para experimentar essas tensões.

Nesse sentido, o que desses cotidianos escolares nos interessa nessa pesquisa? Fundamentalmente as experiências que são criadas nas práticas (inclusivas) pelos professores e alunos que vivem a diferença no dia-a-dia. Assim, um conceito é precioso para tal empreitada: o conceito de experiência.

O conceito de experiência, cuja desnaturalização nos chegou por Jorge Larrosa, a partir do texto "Sobre A Experiência E O Saber De Experiência" (2002) tem provocado - nos últimos anos - muita discussão em diferentes grupos do campo da educação, sendo uma referência quase naturalizada ao escrever, pesquisar, conversar sobre educação. Mas tentaremos brevemente, e nos apoiando no texto de Larrosa, dar uma certa densidade a essa palavra, que muitas vezes é banalizada como sinônimo de acumulação dos anos em certo espaço e como uma prática esvaziada (ou alheia) da sua necessária consideração dramática como teoria em movimento que lhe é inerente.

Larrosa (2002) diz sobre a necessidade de pensar a experiência e desde a experiência e possibilitar, talvez, um pensamento da educação e da pesquisa a partir desse exercício de experimentação. A experiência é isso que me passa, escreve o autor, mas o isso dessa frase supõe, então, um acontecimento, ou seja, o acontecimento de alguma coisa ou de algo que não sou eu. E esse algo que não sou eu significa alguma coisa que não depende de mim, que não é uma projeção minha, que não é o resultado das minhas palavras, nem das minhas ideias, nem das minhas representações, nem dos meus sentimentos, nem projetos, nem das minhas intenções. Que não depende dos meus saberes, nem poderes, nem da minha vontade. Esse "que não sou eu" - para Larrosa - significa que é "outra coisa diferente de mim", outras coisas diferentes das que eu falo, diferentes das que eu sei, diferentes das que eu sinto, penso, antecipo, diferentes do que eu posso, do que eu quero. A isso, o autor (junto com outros) chama de "princípio de alteridade" - ou de exterioridade ou, ainda, de alienação. 
Algumas Implicações Políticas, (Po)éticas e Práticas no Projeto “Diferenças e Alteridade na Educação:...

A experiência, na exterioridade do acontecimento, não deve ser interiorizada, capturada, mas, mantida como exterioridade. Essa alteridade não deve ser identificada, mas, mantida como radical alteridade. A experiência - para Larrosa - não reduz o acontecimento (nem se reduz ao acontecimento), mas, sustenta o acontecimento como irredutível... irredutível às minhas palavras, ideias, projetos, saberes, poderes, e tanto mais...

Mas a experiência supõe, também, em segundo lugar: que algo me passa! Não o que passa na minha frente, mas, a mim, ou seja, em mim. A experiência supõe, então, não um acontecimento exterior a mim, mas a ratificação do lugar da experiência: sou eu! É em mim - ou nas minhas palavras, ou nas minhas ideias, ou nas minhas representações, nos meus sentimentos, nos meus projetos, etc, aonde a experiência tem lugar. Larrosa chama isso de "princípio da subjetividade" ou, também, da reflexividade ou da transformação. Chama dessa forma porque o lugar da experiência é o sujeito, mas trata-se de um sujeito que é capaz de deixar que alguma coisa passe com ele, ou seja, que alguma coisa passe com as suas palavras, com os seus saberes, projetos, representações, com sua vida. Exige pensar na educação não como reconhecimento do mesmo, mas como alteridade.

Trata-se, então, de lidar com aquilo que é do sujeito e não com o que se passa, supostamente, fora dele. Trata-se de um sujeito exposto. Por outro lado - segundo o autor- esse princípio supõe que não há experiência em geral, que não há experiência de alguém: cada um faz e padece a sua experiência. Isso é único e singular. A experiência supõe, também, que algo ou alguma coisa passa desde o acontecimento até mim, que alguma coisa ou algo me vem ou me (ad)vém. Isso pressupõe riscos e perigos.

Se a experiência é isso que me passa, o sujeito da experiência é como um território, no qual isso que passa deixa marcas, rastos, feridas. Isso faz com que, em princípio, o sujeito é um sujeito não ativo senão um sujeito passional: a experiência não se faz, senão que se padece. Esse princípio é chamado por Larrosa de "princípio da paixão".

Saberes das experiências criados no cotidiano escolar.. .mas, focados em que? Nas questões implicadas nas diferenças, na alteridade, na educação. É muito frequente, sobretudo nesta última década, a procura de eufemismos que sejam cada vez mais politicamente corretos para narrar os outros, a alteridade: "necessidades especiais", "sujeitos portadores de deficiências", "diversidade”, "diferença” e tantos outros. Parecem, assim, constituir-se num contínuo de significados mais ou menos parecidos, mais ou menos semelhantes. As pessoas com deficiências e os sujeitos incluídos no discurso da alteridade deficiente são atravessados pelos significados construídos desde a normalidade. Interessa-nos atentar, junto com Carlos Skliar, para o fato da existência 
de uma "confusão" na utilização dos termos deficiência, diversidade e diferença, quando se trata de nomear - produzir, criar- esses outros. O discurso da deficiência tende a mascarar a questão política da diferença que é definida como diversidade, que é entendida, quase sempre, como a variante aceitável e respeitável do projeto hegemônico de normalidade. Neste sentido, algumas marcas de significados que possibilitam a compreensão das diferenças seriam

\begin{abstract}
As diferenças não são uma obviedade cultural nem uma marca de "pluralidade"; - As diferenças se constroem histórica, social e politicamente; - não podem caracterizar-se como modalidades fixas, essenciais e inalteráveis; - as diferenças são sempre diferenças; - não devem ser entendidas como um estado não desejável, impróprio, de algo que cedo ou tarde voltará a normalidade; - as diferenças dentro de uma cultura devem ser definidas como diferenças políticas e não simplesmente como diferenças formais, textuais ou linguísticas; - as diferenças, ainda que vistas como totalidade ou colocadas em relação com outras diferenças, não são facilmente permeáveis nem perdem de vista suas próprias fronteiras; - a existência de diferenças existe independentemente da autorização, da aceitação, do respeito ou da permissão outorgada da normalidade (SKLIAR, 2001, p.98).
\end{abstract}

Neste sentido, a questão da definição de quem são os outros não se resolve pelo fato de encontrarmos termos mais ou menos politicamente corretos senão em "desconstruir a suposta ordem natural dos significados que os localizam em certos discursos e práticas de poder" (SKLIAR, 2001, p.97) e pensar o conceito de diferença não como alguma coisa que substitui, simplesmente, o de diversidade ou de pluralidade, e muito menos, o de deficiência ou necessidades especiais. Esperamos, com esse trabalho, contribuir para essa desconstrução que nos permita pensar o espaço escolar como um espaço de tensões entre lógicas, línguas e desejos que são produzidos em relações de poder e saber e que passam, acontecem, na experiência da alteridade na educação.

\title{
Para fechar: possíveis atravessamentos e desdobramentos...
}

Após alguns meses vinculadas à pesquisa, percebemos três movimentos como desdobramentos do objetivo inicial do nosso projeto: Por um lado, a produção de um espaço de exercício de pensamento sobre o campo a partir da conformação de um grupo de estudos. Por outro lado, um segundo movimento que é a conclusão de um levantamento, através da conversa e da aplicação de questionários, dos interesses e desejos de professores da rede estadual que participam da formação continuada em Educação Especial coordenada por um Núcleo específico dependente da Secretaria de Educação do Estado. Esse procedimento nos permitiu não só a aproximação aos professores que participam dessa instância de formação como possíveis interlocutores, mas, experimentar as tensões, desafios, desorientações, orientações, tentativas, resistências, potencias do próprio processo de formação continuada oferecida pelo núcleo. Por último, a equipe está mergulhada no cotidiano e na memória de uma escola estadual escolhida como lócus da nossa pesquisa. Esta entrada e esta escolha se dá porque, efetivamente, é uma escola 
que se assume como escola inclusiva - com todas suas tensões e implicações- com seis salas de recursos multifuncionais, classes especiais e ainda como espaço de funcionamento de alguns núcleos e centros de atendimento específico de certas deficiências. Ao mesmo tempo, muitos dos professores que participaram do movimento anterior (conversas e questionários na formação continuada) são professores desse centro. No momento da escrita desse texto estamos trabalhando na contextualização do espaço de pesquisa a partir do trabalho com a memória do lugar, encarnada nas narrativas dos professores, diretores, pais, alunos.

Neste movimento da pesquisa por meio da leitura de dois textos produzidos por Carlos Skliar em 2009/ 2010 sentimos a necessidade de fechar esse trabalho lançando algumas anotaçóes para pensar sobre certos acontecimentos materializados em algumas narrativas que encontramos no nosso trabalho cotidiano. Nos três espaços-tempos de pesquisa enunciados acima duas frases aparecem frequentemente na boca de diferentes atores do campo educacional: "o problema de convivência" e "o não estar preparados para..."

Entendemos que a questão da convivência ou do estar juntos na educação não podem, como nos lembra Skliar, ser pensadas como flechas, signos, símbolos ou indicações direcionadas necessariamente para a harmonia, a não conflictividade... Pensando nessa conflictividade aparece a questão da responsabilidade na relação de alteridade: De quem é o problema, a questão da inclusão? A primeira e rápida resposta que aparece, quase que imediatamente, é que essa questão, esse problema é de todos. E, assim, talvez, com essa imprecisão generalizadora, também a complexidade e a seriedade se diluem com rapidez.

Ou talvez, a resposta pensada tenha sido da escola regular, que deve incluir os alunos da educação especial tal como as políticas públicas definem.. Nesse sentido, haveria que revisar qual é a pergunta da inclusão para a que a resposta na escola comum seja, quase sempre, "não estamos preparados para...”

O que significaria a expressão "estar preparados"ou "não estar preparados"?

O que pode se entender dessa afirmação acerca de um suposto "saber fazer" ante cada criança, ante cada corpo, ante cada língua, ante cada aprendizagem, ante cada forma de ser e estar no mundo? Acredito que é um impossível o saber, o se sentir e o estar preparados para aquilo que possa vir...há que enfatizar a ideia de que mais do que estar preparados, antecipados ao que virá -que nunca saberemos o que é- do que se trata é de estar disponíveis para receber a quem seja, a qualquer um, a todos, a cada um. Mas, qual é então o problema? Por que, como professores, não podemos ser responsáveis e estar disponíveis a que alguém, independentemente da sua língua, da sua religião, do seu corpo, esteja aqui? Por que não poderíamos estar disponível e nos sentir responsáveis?"(SKLIAR, 2010, p.162). 
Um estar disponível sobre tudo no sentido de acrescentar, multiplicar, alargar e diversificar a ideia de um aluno tradicional, de um aluno comum, de um aluno normal, bem como, acrescentar, multiplicar, alargar e diversificar a idéia imprópria de uma aprendizagem tradicional, de uma aprendizagem comum, normal?

Toda preparação, toda antecipação, configura só um dispositivo técnico, uma certa racionalidade, mas que não funciona necessariamente como um posicionamento ético com relação aos outros. Por essa mesma razão é que não se trata de que uma formação tenha como base apenas abranger a temática da inclusão, da educação especial, da alteridade nos currículos de formação. Assumimos aqui uma posição em parte contraria à tradição formativa, pois creio que haveria que inverter a lógica entre o saber temático e o saber pedagógico relacional. Perguntamo-nos, "Como habitar, eticamente, esse encontro com o outro? Como evitar a tematização do outro? Como não cair na tentação de confundir a uma pessoa surda com o tema "surdez", a uma pessoa cega com o tema "cegueira”, a uma pessoa negra com o tema "negritude"? (SKLIAR, C., 2010, p.163) e pensamos, junto, que do que se trata é de transformar esse registro que aponta sempre para o outro em uma pergunta que responda permanentemente ao que passa-acontece-entre nós O que passa entre nós... Passa alguma coisa entre nós?

\section{REFERÊNCIAS}

BRASIL.Decreto n 6.094/2007..Brasília, 2007.

BRASIL.Decreto nº 6.571.Brasília, 2008.

BRASIL. Diretrizes Nacionais de Educação Especial para a Educação Básica. Brasília, 2001.

BRASIL. Ministério de Educação. Diretrizes Operacionais para o Atendimento Educacional Especializado na Educação Básica, modalidade Educação Especial.2009.Disponível em:http://portal.mec.gov.br/dmdocuments/rceb004 09.pdf. Acesso em 16/07/2010).

BRASIL. Ministério de Educação. Política Nacional de Educação Especial na Perspectiva da Educação Inclusiva.2008. Disponível em: http://portal.mec.gov.br/seesp/arquivos/pdf/politica. pdf. Acesso em 16/07/2010

BRASIL. Ministério de Educação. Resolução CNE/CEB 2/2001. Diário Oficial da União. Brasília, 14/9/2001. Seção 1E, PP. 39-40, 2001.

BRASIL.Plano Nacional de Educação (Lei no 10.172/01). 2000. 
BUENO, J. G. S. As políticas de inclusão escolar: uma prerrogativa da Educação Especial?In: BUENO, J. G. S.; MENDES, G. M. L.; SANTOS, R. A. dos. Deficiência escolarização: novas perspectivas de análise. Editora Junqueira\&Martin, Brasília, p. 43-66, 2008.

CERTAU, Michel de. A Invenção do cotidiano - artes de fazer. Petrópolis: Vozes, 1994.

LARROSA, Jorge. Notas Sobre A Experiência E O Saber De Experiência. 2002. Disponível em: http://www.anped.org.br/rbe/rbedigital/RBDE19/RBDE19 04_JORGE_LARROSA BONDIA. pdf. Acesso em 27/4/2012.

PEDREIRA, Silvia Maria Fangueiro. Educação Inclusiva de Surdo/as numa Perspectiva Intercultural.ANPED, Caxambú: 2007; Disponível em:http://www.anped.org.br/reunioes/30ra/ trabalhos/GT15-3014--Int.pdf. Acesso em 27/5/2012.

PLETSCH, Márcia Denise. Projeto de Pesquisa "Observatório de políticas públicas em Educação Especial e inclusão escolar: Estudo sobre as políticas públicas e práticas curriculares em Educação Especial e inclusão escolar de alunos com necessidades educacionais especiais nos municípios da Baixada Fluminense"; UFRRJ, 19/5/2010.

PLETSCH, Márcia Denise. Repensando a inclusão escolar: diretrizes políticas, práticas curriculares e deficiência intelectual. Editora EDUR/NAU, Rio de Janeiro, 2012.

SILVA, Shirley. Excluindo armadilhas, incluindo direitos - uma outra leitura da escola e da inclusão. 2007. Disponível em: http://www.alb.com.br/anais16/prog_pdf/prog09_01.pdf. Acesso em $17 / 8 / 2010$.

SKLIAR, Carlos. Perspectivas Políticas e Pedagógicas da Educação Bilíngüe para Surdos. IN: SILVA, Shirley e VIZIM, Marli (orgs.) Educação Especial: múltiplas leituras e diferentes significados.São Paulo: Mercado das Letras, 2001.

SKLIAR, Carlos. A educação e a pergunta pelos Outros: diferença,alteridade, diversidade e os outros "outros". 2003. Disponível em: http://www.perspectiva.ufsc.br/pontodevista 05/03 skliar.pdf. Acesso em 27/4/2012.

SKLIAR, Carlos. Juzgar la normalidade no la anormalidade. Políticas y falta de políticas en relación a las diferencias en educación. 2005. Disponível em: http://www.espaciologopedico. com/recursos/listaarticulos2.php?Id autor=54\&action2=4\&palabra=Carlos\%20Skliar. Acesso $27 / 4 / 2012$.

SKLIAR, Carlos. De la crisis de la convivencia y el estar juntos en educación. Revista d'Innovació i Recerca en Educació, 3 (2):1-12. 2009. 
RIBETTO, A.

SKLIAR, Carlos. De la razón jurídica hacia una ética peculiar. A propósito del informe mundial sobre el derecho a la educación de personas con discapacidad. Política y Sociedad, 2010, Vol. 47 Num. 1: 153-164.

UNESCO. Declaração de Salamanca e Linha de Ação sobre Necessidades Educativas Especiais.Brasília: CORDE, 1994.

Submetido em: 04/2012

Aprovado em: 06/2012 